\title{
O professor de Matemática do ensino médio e as tecnologias de informação e comunicação nas escolas públicas estaduais de Goiás
}

\author{
Abadia de Lourdes da Cunha ${ }^{1}$, Maria Gonçalves da Silva Barbalho², Liberalina Teodoro \\ de Rezende ${ }^{3}$, Rildo Mourão Ferreira ${ }^{4}$
}

bacunha6@hotmail.com, rildomourao@uol.com.br

mariabarbalho2505@gmail.com,

libeteodoro@gmail.com,

\begin{abstract}
${ }^{1}$ Docente da Secretaria de Estado de Educação de Goiás. Discente do Programa de Pós-graduação em Sociedade, Tecnologia e Meio Ambiente - UniEVANGÉLICA. Anápolis-Goiás-Brasil.

${ }^{2}$ Docente do Programa de Pós-graduação de em Sociedade, Tecnologia e Meio Ambiente UniEVANGÉLICA- Anápolis-Goiás-Brasil.

${ }^{3}$ Docente da Universidade Estadual de Goiás. Discente do Programa de Pós-graduação de em Sociedade, Tecnologia e Meio Ambiente - UniEVANGÉLICA.

${ }^{4}$ Docente do Programa de Pós-graduação de em Sociedade, Tecnologia e Meio Ambiente UniEVANGÉLICA- Anápolis-Goiás-Brasil.
\end{abstract}

DOI: 10.17013/risti.e4.1-15

Resumo: Este artigo apresenta o resultado final da minha dissertação de mestrado “As tecnologias de informação e comunicação nas escolas públicas estaduais em Goiás o que dizem os professores de Matemática do ensino médio" e tem como objetivo analisar o uso das TIC no processo de ensino e aprendizagem de Matemática no ensino médio nas escolas públicas estaduais de Goiás. A metodologia utilizada consistiu-se de uma abordagem de caráter qualitativo e quantitativo com revisão bibliográfica, trabalho de campo realizado em cinco colégios localizados nas Mesorregiões do Estado. Os resultados revelam um quadro preocupante no que se refere ao processo de ensino e de aprendizagem de Matemática através da inclusão das TIC na educação, como a falta de estrutura física, da formação continuada dos professores para o uso das TIC e de políticas públicas educacionais bem planejadas acabam por desenhar o mapa da não inclusão das TIC nas ações pedagógicas dos professores.

Palavras Chave: Tecnologia; ensino e aprendizagem; formação de professor de Matemática e infraestrututa.

\section{Mathematics teacher high school in public schools of Goias and the information and communication technologies}

\begin{abstract}
This article presents the final result of my master thesis "Information and communication technologies in the public schools of Goias. - what say high school mathematics teachers' and aims to analyze the use of ICT in the teaching process and mathematics learning in high school in the public schools of Goias. The methodology consisted at a qualitative approach and quantitative, utilizing
\end{abstract}


bibliography review and fieldwork carried out in five schools located at the State Mesoregions. The results reveal a worrying situation in relation to the teaching process and mathematics learning through the inclusion of ICT in education, such as lack of physical infrastructure, educational policies as well planned and ongoing training of teachers to use ICT, end up drawing the map of non-inclusion of ICT in educational activities of teachers.

Keywords: Technology; teaching and learning; teacher training in Mathematics and infrastructure.

\section{Introdução}

A aprendizagem dos conteúdos de Matemática tem sido há muito tempo questões de discussão entre pesquisadores, gestores, professores, pais e sociedade em geral. Questiona-se o porquê das dificuldades dos alunos e buscam-se alternativas pedagógicas para sanar a situação que hoje se encontra o processo de ensino e aprendizagem da Matemática.

Os dados sobre o ensino de Matemática no Brasil revelam resultados insatisfatórios e dentre as causas apontadas por Vitti (1999) e Rodrigues (2001), destaca-se a rejeição da disciplina pelos alunos em todas as classes sociais e em todos os níveis de ensino. As principais causas dessa rejeição, segundo Reis (2005), é a falta de motivação do professor para ensinar e a falta de motivação dos alunos em aprender - devido à ideia pré-concebida e aceita pelos alunos de que a Matemática é difícil - as experiências negativas que os alunos tiveram com essa matéria, a falta de relação entre a Matemática ensinada na escola e o cotidiano do aluno, a prática do professor, pelas relações estabelecidas com os alunos, à forma como ensina, avaliar e também pelo rigor que a disciplina exige.

Mudanças no processo de ensino e aprendizagem de Matemática estão sendo discutidas por pesquisadores ao longo dos últimos anos, não apenas no que se refere a conteúdo, mas também no que se refere a objetivos e a metodologias. D’Ambrosio (2002) considera que a Matemática é sem dúvida uma das matérias mais temidas pelos alunos, e que a utilização das tecnologias e da informática nas aulas pode ser um excelente meio para a construção do conhecimento, como também uma fonte metodológica para ajudar no processo de ensino e aprendizagem, além de auxiliar no desenvolvimento da autonomia dos alunos. Porém, o autor salienta que as ações devem ser planejadas. Deve-se pensar também nas políticas públicas de investimento para a formação continuada de professores, proporcionando aos docentes condições técnicas e didático-pedagógica bem como na infraestrutura física, com meios computacionais (hardware) e/ou de programas (software) adequados.

Pretende-se neste artigo verificar a inclusão ou não inclusão das tecnologias digitais no processo de ensino e aprendizagem de Matemática na rede pública de educação do Estado de Goiás e como os professores de Matemática do ensino médio tem organizado sua prática docente com o auxílio dessas tecnologias nos anos de 2013 e 2014. Para tanto, foram selecionados 5 (cinco) colégios, cada qual localizado em uma das Mesorregiões goianas, situados nas cidades de Catalão, de Goiânia, de Jussara, de Luziânia e de Porangatu, conforme figura 1.

Para a seleção dos municípios e respectivos colégios, observou-se a distribuição das Mesorregiões do Estado de Goiás, a representatividade do município junto a Seduce Secretaria de Estado de Educação, Cultura e Esporte de Goiás - e os Colégios que contam 
com laboratório de informática e oferecem a $3^{\mathrm{a}}$ série do ensino médio. A seleção dos professores, do grupo gestor e dos alunos foi relaizada por meio de convite feito durante as visitas aos Colégios. O representante do grupo gestor foi indicado pelo Diretor. Os professores de Matemática foram escolhidos entre o grupo de professores e os a turma da $3^{\mathrm{a}}$ série foi indicada pelos professores de Matemática e pelo coordenador pedagógico. A participação dos alunos foi voluntária.

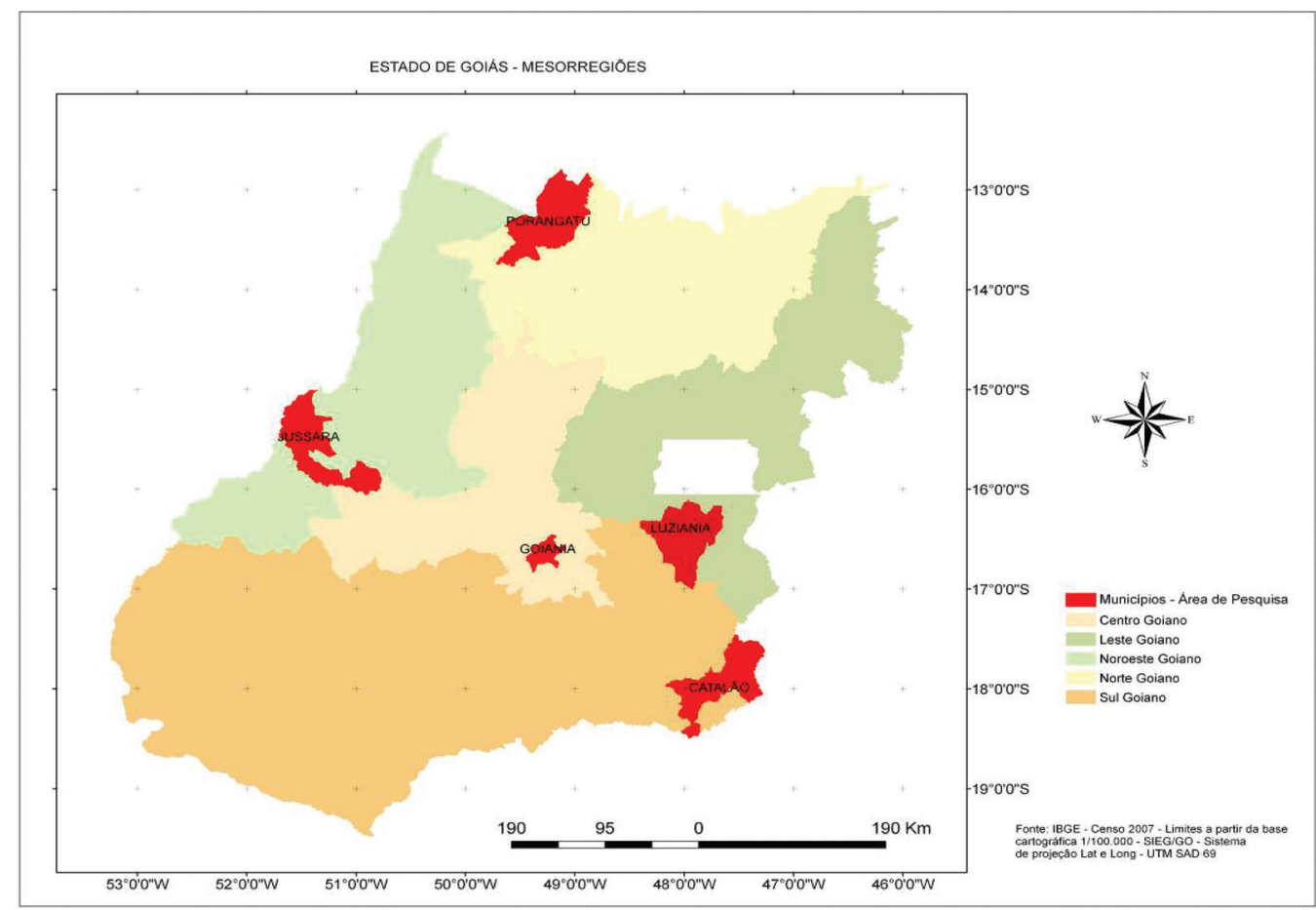

Figura 1 - Municípios das Mesorregiões do Estado de Goiás - área da pesquisa - 2014.

\section{O professor de Matemática, o processo de ensino e aprendizagem e as TIC.}

Ser professor exige muito mais do que ter somente conhecimento sobre sua área específica. É preciso instigar, motivar o aluno a construir o conhecimento. O professor tem que ensinar o aluno a pensar, a descobrir. Mas para isso, ele tem que quebrar os velhos paradigmas da escola tradicional, deixando de ser somente um transmissor de informações. A educação bancária citada por Freire (2003), conhecida por conceber os alunos como meros telespectadores que deveriam absorver tudo conforme as concepções de seus professores sem questionar, não é mais aceita. 
Para Colette (2014) em qualquer tempo e especialmente na atualmente denominada "sociedade do conhecimento", a educação deve corresponder à aprendizagem para a mudança, o que significa dizer aprendizagem para o enfrentamento das mudanças aceleradas que o desenvolvimento tecnológico impulsiona na atualidade. $\mathrm{O}$ autor complementa trazendo a visão de Paulo Freire com trecho dos seus escritos "Educação e Mudança” do ano de 1981, onde Freire diz que a educação para se enfrentar o processo de mudança promove a formação da uma consciência crítica, como instrumento maior para a efetivação de transformações significativas, tanto no plano individual quanto no plano global da sociedade.

Atualmente, verifica-se a necessidade de uma horizontalidade no processo de ensino e de aprendizagem, em que todos devem ser agentes desse processo. Segundo Freire (1999) o diálogo é uma relação horizontal. Nutre-se de amor, humildade, esperança, fé e confiança. Nas palavras de Freire, percebe-se o vínculo entre o diálogo e o fator afetivo que orientará o valor essencial do diálogo em relação aos educandos que não se posicionarão meramente como receptores, mas como indivíduos participantes.

Segundo Andrade (2011) no mundo de hoje, as tecnologias são indispensáveis na educação das crianças e dos adolescentes. Eles 'vivem' tecnologias e quem não ‘vive, ' sonha em viver. É o mundo deles. Isto é fato. Como ignorar este "potencial?”. Na busca da quebra desse paradigma, não basta só conscientizar a sociedade é preciso formar os educadores.

Em ambientes informatizados atribui-se grande ênfase aos recursos usados no processo ensino e aprendizagem do ponto de vista construtivista, amparados pela concepção de que o conhecimento é construído a partir de percepções e ações do sujeito, constantemente mediadas por estruturas mentais já construídas ou em construção, em consonância com o próprio processo de aprendizagem. Gravina (1998) afirmam que, na perspectiva construtivista, a aprendizagem da Matemática depende de ações que caracterizam o fazer Matemática: experimentar, interpretar, visualizar, induzir, conjecturar, abstrair, generalizar e demonstrar. É o aluno agindo, diferentemente de seu papel passivo frente a uma apresentação formal do conhecimento, baseada essencialmente na transmissão ordenada de fatos, geralmente na forma de definições e propriedades.

Para Assis (2009) existe atualmente uma diversidade de equipamentos e meios que propiciam inovações para as diversas áreas do conhecimento. Para a Matemática existem inúmeros softwares, dentre eles citamos o Geogebra, o Cabri-Géomètre, o LOGO e o Círculo Trigonométrico, que auxiliam na editoração de fórmulas, nos desenhos gráficos, geométricos, entre outros. Também são utilizados métodos audiovisuais através de fitas VHS ou CDs que são populares, com dinâmicas ou traços do ramo geométrico que fazem parte do dia a dia. As apresentações de filmes, entrevistas e documentários apresentam um resultado bastante positivo em relação à atenção dos alunos.

Nesse sentido Guajardo (2001) diz que o professor de Matemática precisa entender que o recurso tecnológico como todas as ferramentas produzidas pelo ser humano pode ser usado para construir o progresso, combater iniquidade e dar maiores oportunidades às novas gerações. Para utilizar as tecnologias é necessário ter consciência para que não se amplie a distância social do sistema educativo em termos de qualidade do ensino e de oportunidades aos estudantes. O professor precisa da legitimidade educacional na inclusão do computador, da 
internet, de software em suas ações pedagógicas, sendo essencial saber estabelecer links entre as TIC e o conhecimento matemático, possibilitando assim a construção de conhecimento. O domínio do técnico e do pedagógico não deve acontecer de modo estanque, um separado do outro Valente (2005). Ou seja, não adianta dominar a tecnologia se não se tem a pedagogia de um professor e vice-versa.

É necessário desenvolver capacidades que possibilite ao professor manusear os aparatos tecnológicos, para que ele possa se comunicar e interagir no mundo virtual. O letramento digital passa a ser um pré-requisito fundamental, uma necessidade educacional e de sobrevivência para a inclusão digital e nesse contexto a escola tem um papel fundamental, pois tem como missão formar cidadãos para a sociedade, para vida. A escola precisa preparar o aluno, para que ele possa utilizar de maneira significativa os recursos tecnológicos, fazendo emergir a autonomia, a cooperação e a curiosidade, participando ativamente da construção do "aprender a aprender", indo ao encontro da necessidade de ensinar aprendendo ou aprender ensinando.

\section{A construção do objeto de pesquisa, o perfil do professor e as categorias de análise}

A abordagem metodológica adotada na pesquisa fundamentou-se na análise qualitativa e quantitativa a partir da revisão bibliográfica, trabalho de campo, com questionários semi-estruturados aplicados aos gestores dos colégios (5), aos professores de Matemática(11) e aos alunos da $3^{\mathrm{a}}$ série do enino médio (89) e entrevista aplicada aos mesmos professores. Totalizando 105 pessoas entrevistadas.

Para Reis (2014) a utilização de uma abordagem metodológica que utilize as valências dos métodos qualitativos e quantitativos, é uma prática comum e bastante em voga na área das ciências sociais. Faz referências a outros autores como Pope e Mays, onde afirmam que os dois métodos não se excluem, apesar de diferirem na forma e na ênfase, e a adição de métodos qualitativos contribui para uma melhor compreensão dos fenómenos por via de um cunho racional e intuitivo bem como do estudo de relações de nexo causal.

A pesquisa obedeceu quatro etapas:

- inicialmente, foi realizada a revisão bibliográfica no qual foram consultados artigos científicos, publicados em anais de congressos, em revistas científicas com classificação Qualis, dissertações e teses, dentre outras fontes que retratassem o tema em estudo. Posteriormente, foi definido o recorte espacial, temporal e os atores envolvidos na pesquisa. A definição do "campo de observação" além do local (recorte espacial) e circunstâncias (recorte temporal), a delimitação da população a ser estudada é de fundamental importância para uma boa leitura dos fatos (GIL, 2010; RUDIO, 1985; entre outros);

- elaboração dos questionários e da entrevista - foram elaborados e utilizados como instrumentos da pesquisa três questionários, que foram aplicados ao grupo gestor, aos professores e alunos. O questionário aplicado ao gestor teve como objetivo conhecer a estrutura física, de pessoal e pedagógica da escola, bem como os recursos tecnológicos, Internet disponíveis e utilizados pelos 
professores com os alunos, e o trabalho desenvolvido pelo Grupo Gestor do Colégio para a melhoria do ensino e aprendizagem. O questionário aplicado ao professor teve como objetivo identificar a formação dos professores de Matemática do Ensino Médio Estadual de Goiás, bem como os recursos tecnológicos disponíveis e utilizados pelos professores com os alunos. O questionário aplicado aos alunos teve o propósito de identificar o perfil dos alunos, a partir dos dados socioeconômicos e culturais, bem como informações sobre a utilização das tecnologias e Internet na escola, especialmente nas aulas de Matemática. As entrevistas foram realizadas como os professores e teve objetivo de obter maiores informações sobre o processo de ensino e de aprendizagem, sobre a formação continuada, sobre as atividades acadêmicas dos professores de Matemática do Ensino Médio Estadual de Goiás, bem como dos recursos tecnológicos disponíveis e utilizados pelos professores com os alunos;

- trabalho de campo realizado nos cinco colégios selecionados para a realização da pesquisa foi feito por meio de visitas nos colégios com objetivo de realizar entrevistas, aplicar os questionários aos gestores, professores e alunos. Também foram tiradas fotografias para registrar a situação das escolas no momento da visita.

- tratamento dos dados coletados que foram transformados em categorias de análises. Ludke (1986) salientam que para a construção das categorias de análise, as unidades de significado podem ser combinadas para formar conceitos mais abrangentes ou ideias muito amplas, ou podem ser subdivididas em componentes menores para facilitar a composição e apresentação dos dados. As subcategorias estão devidamente inseridas dentro das categorias préexistentes, conforme os objetivos da pesquisa. Assim, tendo como referência os autores acima citados, optamos por dividir as subcategorias dentro das categorias pré-existentes, a saber: 1) Formação dos professores; 2) Processo ensino e aprendizagem: Dificuldade na aprendizagem, desempenho dos alunos e relação professor aluno na construção do conhecimento; 3) Inclusão das TIC nas práticas pedagógicas: Contatos com as TIC, planejamento das atividades acadêmicas, projeto político pedagógico e currículo; 4) Estruturas dos Colégios em relação às TIC: Pessoal, equipamentos tecnológicos e ações pedagógicas desenvolvidas no colégio e 5) Perfil socioeconômico e cultural dos alunos em relação às TIC: Situação familiar do aluno, vida financeira, situação escolar e lazer preferido e contato com as TIC.

\subsection{Perfil do professor}

Dos 11 professores pesquisados, seis são do sexo masculino cinco do sexo feminino. $64 \%$ deles estão na faixa etária de 41 a 50 anos e 36\% estão entre 30 a 41 anos. Sobre o fator experiência como professor de Matemática, 72\% dos professores têm de 11 a 25 anos, dois professores tem de 06 a 10 anos e um com mais de 25 anos.

\subsection{Perfil dos gestores}

Foram pesquisados cinco profissionais, quatro são do sexo feminino e um do masculino. Um com idade menor do que 30 anos; dois entre 31 a 40 anos e dois com idade entre 
41 a 50 anos. Todos possuem graduação; 60\% especialização, 20\% mestrado. Um dos pesquisados exerce a função de secretário geral, um de professor, um coordenador pedagógico, um vice-diretor e um diretor. Em relação ao tempo de trabalho na educação: $20 \%$ com menos de dez anos, $40 \%$ entre 11 a 20 anos e os outros $40 \%$ possuem mais de 20 anos na educação.

\subsection{Perfil dos alunos}

Em relação aos 89 alunos pesquisados, todos são do turno matutino, 48 são do sexo feminino e 41 do sexo masculino, 27 estão na faixa etária dos 16 anos, 49 estão na faixa etária de 17 a 18 anos, 11 entre 19 a 24 anos e dois estão acima de 24 anos.

\subsection{Categorias de análise}

\subsubsection{Formação dos professores.}

As respostas dos entrevistados revelam um ponto bastante positivo, que os professores possuem formação acadêmica e especialização. Questão o3: composta pelos itens graduação, especialização e formação para as TIC. Observou-se que $100 \%$ dos professores possuem Licenciatura em Matemática, 91\% deles com especialização e 56\% possuem cursos na área das TIC. Com relação às questões 19 "A Seduc oferece formação continuada para o uso das NTIC?” e questão 20 "Os professores desse colégio participam de cursos de formação continuada para o uso das NTIC?” 80\% dos gestores disseram que a Seduce oferece esses cursos e quando perguntados se os professores participam desses cursos 40\% disseram que sim, 40\% disseram que não e 20\% não responderam esse item. Questão 5 - Em sua opinião é necessário promover momentos de estudos teóricos e de orientação prática para o uso das NTIC em sala de aula? O que acha da ideia de apresentar aos seus alunos alguns conteúdos curriculares de Matemática, aplicando uma atividade previamente planejada fazendo uso das NTIC como material didático? As respostas obtidas mostram a preocupação dos professores sobre a formação, já que 100\% deles disseram que sim. De acordo com um dos professores é nos momentos teóricos que se consegue elaborar melhor o planejamento. Segundo ele, saber planejar é muito importante, e essas discussões com outros professores da área e de áreas afins enriquecem e muito o trabalho. O professor ainda argumenta que esses momentos teóricos de formação e de troca são os que podem nos capacitar para trabalhar novas experiências, e a inclusão das tecnologias é uma delas.

Nos relatos dos professores observa-se que todos sentem a necessidade de formação continuada. E quando essa formação refere-se ao uso das TIC nas atividades acadêmicas escolares, torna-se mais urgente considerá-la como ação pedagógica, pois os professores têm dificuldades tanto estruturais como de formação para essa ação. Percebe-se que há uma equidade entre os professores que possuem formação na área das TIC e os que não têm formação. Outro fator relevante e que precisa ser revisto é a não continuidade dos programas desenvolvidos pelos NTEs, conforme observaram dois professores "Temos somente um curso básico (do NTE) para o uso das tecnologias. Precisamos de formação completa. Até começamos um curso pelo NTE, mas não teve continuidade, precisamos de ações que finalizem, de propostas que sejam bem planejadas e que tenham inicio, meio e fim". 
Candau (1997) apresenta três aspectos fundamentais para o processo de formação continuada de professores: a escola, como lócus privilegiado de formação; a valorização do saber docente; e o ciclo de vida dos professores. Isto significa dizer que a formação continuada precisa: primeiro, partir das necessidades reais do cotidiano escolar do professor; depois, valorizar o saber docente, ou seja, o saber curricular e/ou disciplinar, mais o saber da experiência; por fim, valorizar e resgatar o saber docente construído na prática pedagógica (teoria + prática).

\subsubsection{Processo ensino e aprendizagem.}

Essa categoria foi dividida em outras três subcategorias. A primeira com foco na dificuldade de aprendizagem, que busca respaldo na entrevista com os professores na questão o1 - "Na sua concepção quais os principais fatores que dificultam a aprendizagem do aluno?” As respostas apontam uma série de fatores que deixaram os professores bastante preocupados. A "falta de compromisso, interesse e foco" com (73\%), "falta de conhecimento sobre conteúdos básicos de Matemática" (63,64\%). Os itens: "falta de disciplina dos alunos" e as questões relacionadas ao "currículo extenso", que dificulta a retomada de conteúdos básicos que os alunos desconhecem, relacionados ao "Sistema de ensino deficitário" e as "exigências do Sistema de ensino" acabam por engessar o professor, representam (45,45\%). Outro fator preocupante é a "falta da família na escola" (36,36\%) que tem ligação direta com os "fatores sociais, com problemas estruturais, financeiros e drogas" (9,09\%). Questiona-se também o "ensino de Matemática sem significado, fora do contexto do aluno", com 9,09\%. Os professores chamam a atenção sobre os problemas sociais, falta de estrutura do sistema de ensino e a falta do envolvimento da família na vida dos seus filhos, dentro e fora da escola.

A segunda subcategoria refere-se às questões 21, 22, 24 e 25 do questionário do professor que apresentam a dimensão sobre o desempenho dos alunos. E as questões aplicadas aos alunos de 17 a 19 anos. Na análise da questão 21 "O interesse dos alunos nas aulas expositivas de Matemática utilizando livros/apostilas e lousa é considerado pelo professor: bom ou satisfatório constatamos que (91\%) dos entrevistados consideram satisfatório enquanto que $9 \%$ diz que não é satisfatório. Com relação à questão 22 "O interesse dos alunos nas aulas de Matemática utilizando as NTIC demonstra ser:" Seis professores responderam que consideram satisfatório, um professor respondeu não ser satisfatório enquanto que quatro professores responderam que não utilizam as NTIC nas suas aulas. A questão 24 "A aprendizagem dos alunos é melhor quando"? Um dos professores respondeu que os alunos apresenta o mesmo interesse das aulas expositivas (utilizando livros, apostila e lousa) nas aulas em que utiliza as NTIC. 64\% dos pesquisados disseram que a aprendizagem é melhor quando utilizam as NTIC e dois disseram que a aprendizagem é melhor nas aulas expositivas utilizando livros, apostila e lousa. A questão 25 "Na sala de aula quando utilizam a internet (sem bloqueio) o que os alunos mais acessam:" $72 \%$ dos professores disseram que são as redes sociais e três deles afirmaram não utilizar a internet nas aulas.

Questão 17 "Em sua opinião as atividades desenvolvidas pelo professor no laboratório de informática utilizando as novas tecnologias/internet contribui para o seu aprendizado?” e questão 18 "Em sua opinião as atividades desenvolvidas pelo professor, utilizando algum recurso tecnológico contribuem para o seu aprendizado?”. No que se refere ao uso do laboratório de informática os alunos ficaram divididos entre dizer o que eles pensavam ser melhor ou sobre a realidade da não utilização do laboratório. No entanto, 92,13\% 
acreditam que as atividades com recursos tecnológicos contribuem para o processo ensino e aprendizagem. Questão 19 "Qual o tipo de aula que você mais gosta e que aprende a matéria com mais facilidade?" $57,30 \%$ dos alunos responderam que é com aulas expositivas quanto o professor utiliza a apostila e livro didático, (42,30\%) responderam que são nas aulas que o professor utiliza software e vídeos. Verificou-se durante aplicação dos questionários que os alunos tinham dúvidas de como responder as questões porque não conseguiam imaginar como seriam as aulas com a utilização das NTIC. Pode-se observar também pelas manifestações dos pesquisados que eles sentem a necessidade da inclusão das NTIC para deixar os conteúdos mais fáceis de serem assimilados.

A relação professor aluno na construção do conhecimento é a terceira subcategoria, relacionada à questão 02 da entrevista. "O que pode facilitar na relação do professor de Matemática com seus alunos para que aconteça a construção de conhecimento de forma eficaz?”. Nos relatos fica evidente a necessidade de uma relação mais saudável (com respeito, confiança, etc.) entre alunos e professores para que se tenha uma boa convivência, o que facilitaria muito no processo de ensino e de aprendizagem. Há a necessidade de o professor ter melhores condições de trabalho para entender/ conhecer melhor a realidade dos alunos dentro e fora da escola, como também a necessidade de uma maior convivência com os colegas de trabalho. Outro fator que merece destaque é a importânciua de se fazer um bom planejamento, e para isso, o professor deve conhecer o público com o qual irá trabalhar, deve incluir os alunos no processo de construção do conhecimento. Segue uma resposta do professor que mostra a importância do diálogo, da boa relação e do envolvimento do professor com seus alunos. "A boa convivência depende dos dois lados, do professor e do aluno. Para ter uma aproximação e para que essa facilite no aprendizado, é necessário abertura do aluno e um bom preparo do professor. Levando para o lado das tecnologias, sabemos que ela não é solução para a educação, mas pode ser um mecanismo para unir professor e alunos, e causar efeito no ensino, pois nosso aluno está muito familiarizado com o computador, com a internet, com o celular. Então precisamos aprender a usar de forma a dar significado aos conteúdos para os alunos”.

Para Tacca (2006), o diálogo é um momento de troca de intimidades que não admite autoritarismo, negligência ou protecionismo; sendo uma ocasião em que se viva a intersubjetividade na responsabilidade mútua. O processo educativo se compõe de forma que tanto alunos como professores devem estabelecer dentro de sala de aula um relacionamento que envolva compromisso e responsabilidade a fim de se almejar uma relação de confiança mútua. Para Libâneo (1991) a compreensão por parte do professor a cerca das condições dos alunos se faz fator fundamental para o estabelecimento de relações sociais entre ambos os sujeitos envolvidos. O sucesso na aprendizagem tem como fator essencial o estabelecimento de um diálogo que para que aconteça a interação entre o professor e seus alunos, com o objetivo a compreensão do outro em sentidos socioeconômicos e culturais.

\subsubsection{Inclusão das TIC nas práticas pedagógicas.}

Sober o contato dos professores com as TIC. Questão 5 “Tem computador” e questão 6 "Acessam a internet" todos os professores responderam que sim para os dois questionamentos. As resposta dadas à questão 7 "Nível de conhecimento com a internet" demonstra que 45,45\% dos entrevistados possuem nível básico, 18,18\% possuem nível 
médio, 9,09\% são especialistas e 27,27\% possuem nível avançado. Questão 8 “Tem acesso e utiliza software de Matemática?” todos afirmaram que têm acesso e utilizam software de Matemática em residências e aproximadamente $73 \%$ afirmaram que não utilizam no trabalho. Questão 9 "Sobre as NTIC, como se sente" cerca de 64\% respodneram que se sentem despreparados para utilizar as NTIC e necessitam de orientação dos profissionais especializados enquanto que $36 \%$ afirmaram estarem preparados para utilizar as NTIC na sala de aula.

O planejamento das atividades acadêmicas. A subcategoria planejamento das atividades estão nas questões de 10 a 14 e na 23 do questionário aplicado ao professor e na questão 15 do questionário aplicado ao grupo gestor. Questão 10 "É útil para as suas atividades profissionais e pessoais saber usar o computador?" 100\% dos professores afirmaram que sim. Questão 11 "Você usa o computador preferencialmente para que?" todos afirmaram que o utiliza, preferencialmente, como recurso didático e como fonte de informação. Questão 12 "Você planeja suas aulas a partir dos recursos tecnológicos disponíveis na sua escola?" 45,45\% dizem que sim, o mesmo percentual afirmou que não e um entrevistado afirmou que planeja o uso de aplicativos para demonstrar e exemplificar os conteúdos. Questão 13 "Que percentual de aulas mensais são planejadas com a utilização das NTIC?" 82\% dos entrevistados responderam que planejam até 5\% das aulas anuais com a utilização das NTIC, $9 \%$ responderam que planejam $6 \%$ a 10\% das aulas utilizando as NTIC e um dos entrevistados planeja de 29\% a 35\% das aulas com a utilização das NTIC. Questão 14 “Quais recursos tecnológicos utiliza nas aulas?” oito professores indicaram páginas da web para pesquisa. Um professor, além das páginas da web, utiliza software e blogs, dois utilizam software, não especificando quais. A questão 23 "Quais atividades você prepara para os alunos com o uso do computador?” Três professores não utilizam e oito indicam as páginas da web para pesquisa, desses apenas um utiliza software e blogs, dois utilizam apenas software. Os professores não especificaram quais os softwares e blogs que utilizam.

A questão 15 do questionário do gestor "O planejamento das atividades docentes é realizado?” todos responderam que é realizado tanto individualmente como de forma coletiva.

A questão 3 do questionário dos professores “A utilização das NTIC na Educação como ferramentas de ensino vem se mostrando cada vez mais presente na educação de um modo em geral. Você desenvolve atividades com seus alunos utilizando as NTIC nas suas aulas? Se sim, pode nos dizer quais?” A resposta de dois professores sintetiza bem a realidade. "Usamos muito pouco, cerca de 5\% das nossas aulas, e isso no máximo, pois existem muitos entraves para podermos trabalhar com essas ferramentas. Falta estrutura física (equipamentos e capacidade da internet), estrutura de pessoal (há dois anos, desde o ano de 2012, não há os dinamizadores, pessoal essencial na execução das nossas atividades) e a nossa formação enquanto professores é bem básica, estamos desestimulados, com tantas dificuldades acabamos trabalhando o tradicional que não tem surtido muito efeito na aprendizagem". "Sabemos que para se trabalhar com software, com internet, com as tecnologias, precisamos de todo um planejamento, precisamos traçar bem os objetivos, porque senão só mudamos de aparato, de ferramenta, do quadro negro, para o computador, sem mudar a metodologia. Tenho conhecimento, me 
sinto preparado, com uma boa formação, mais por outros fatores não temos utilizado quase nada. Falta-nos estrutura física e de pessoal”.

Sobre o Projeto político pedagógico e o currículo. As questões 18 e 19 do questionário do professor e questão 16 do questionário do gestor abordam o tema "Projeto Político Pedagógico”. Questão 18 “ O plano de ensino que você elabora no início do ano letivo contempla o uso das NTIC?” Sete professores disseram que não, e quatro que sim. Questão 19 “O Projeto Pedagógico da sua escola contempla o uso das NTIC na educação?” Oito dos professores entrevistados disseram que sim, três respodenram que não e três responderam que o projeto político pedagógico do colégio não contempla a inclusão das NTIC na educação. A questão 16 do grupo gestor - "O Projeto Pedagógico é discutido periodicamente pelos pares do Colégio?” 80\% dos gestores responderam que sim, enquanto que 20\% que responderam que não.

Percebe-se que todos os professores têm computadores e acesso à internet e que o nível de conhecimento com a internet da maioria é básico. Observa-se que não estão preparados para utilizar as NTIC e necessitam de orientação dos profissionais especializados. $73 \%$ dos professores não utilizam nenhum software de Matemática em suas aulas e aproximadamente $82 \%$ ministram até $5 \%$ das aulas anuais planejadas com a utilização das NTIC. E quando são questionados sobre quais recursos e atividades envolvendo as NTIC prepara para seus alunos, a grande maioria diz utilizar as páginas da web para pesquisa.

Vale ressaltar que alguns fatores são essenciais para a inclusão das novas tecnologias em sala de aula: que a escola tenha os recursos, que os educadores saibam e queiram utilizá-los e os investimentos pelos órgãos governamentais, nas estruturas físicas e nas políticas públicas de capacitação dos profissionais da educação. O objetivo do professor ao utilizar a tecnologia como mecanismo metodológico no processo de ensino é obter um melhor desempenho dos alunos, isto é, que os auxilie. Segundo Cachuput (2005), para que essas tecnologias contribuam para a aprendizagem do aluno é necessário criar ambientes especialmente destinados à aprendizagem mediada pelo seu uso, em que os alunos possam construir e (re) construir seus conhecimentos de forma cooperativa e interativa, não deixando de lado os estilos individuais.

\subsubsection{Estruturas dos Colégios em relação às TIC.}

Estrututa de Pessoal. O total de alunos matriculados no ano de 2014 nos colégios era 4.446, todos os colégios ofereciam o ensino médio e apenas quatro, o ensino fundamental. $\mathrm{O}$ número de professores era de 235 e contavam com 133 turmas com aulas.

Sobre os equipamentos tecnológicos existentes nos colégios. "Quais as tecnologias que o Colégio possui para as atividades dos professores com os alunos?” Todos possuem vídeo cassete, retroprojetor, datashow, som, computadores e notebook, um ainda possui filmadora e outro possui lousa digital. Essa última ainda não foi utilizada, continua lacrada pelo fato de o grupo de professores não saberem como utilizá-la. Questão 13 "O Colégio tem laboratório de informática?" 100\% disseram que sim. Questão 14 "O Colégio possui profissional, técnico especializado em NTIC para suporte no laboratório de informática?” quatro entrevistados responderam que não possuem. Um dos entrevistados disse que só tem assistência do técnico da Secretaria. Na época da visita, dois Colégios estavam com apoio no laboratório de um 
técnico em informática que cumpria pena alternativa, e conseguia aos poucos colocar alguns computadores funcionando precariamente.

Questão 15 “Possui computadores disponíveis na escola?” Todos os entrevistados responderam ter acesso a computadores na administração, na sala dos professores e nos laboratórios. No entanto, salientaram que os computadores dos laboratórios em sua grande maioria não funcionam, são ultrapassados e não possuem programa apropriado para baixar softwares. Questão 16 "Você considera que os recursos informáticos da sua escola são suficientes para utilização na ação docente?” Quatro professores disseram que não e sete disseram que sim. No entanto, as ações eram para preparar as aulas, preencher os documentos exigidos pela Secretaria, não para trabalhar diretamente com os alunos. Questão 17 “A falta de computadores tem se revelado uma dificuldade em sua ação docente?” Cinco docentes disseram que têm computadores interligados a internet, com softwares específicos, mas não os utilizam nas atividades com os alunos, seis dizem não faltar computadores, mas que esses não são interligados a internet e não tem como instalar software.

No relato dos professores percebe-se que todos sabem da necessidade de oferecer novas formas de apresentar os conteúdos de Matemática para seus alunos, até já o fazem, buscam dentro de suas limitações diversificarem suas aulas, porém sem o uso das TIC.

Ações pedagógicas desenvolvidas no colégio. Quando perguntados sobre as ações pedagógicas desenvolvidas no Colégio com projetos coletivos interdisciplinares, todos os entrevistados responderam que executam ações interdisciplinares por meio dos projetos "Círculo do Diálogo", "Feira das Nações”, "Mais Educação", "Jovem do Futuro", "Dia da Matemática” e "Dia do Meio Ambiente". E não existem projetos coletivos no Colégio que trabalham com o uso das NTIC. Segundo 80\% dos entrevistados, a Seduc oferece formação continuada para o uso das NTIC aos professores. Em relação aos professores dos Colégios pesquisados, 40\% deles participam dessa formação, 40\% não participam e 20\% não responderam esse item.

\subsubsection{Perfil socioeconômico e cultural dos alunos em relação às TIC}

A amostra dos 89 alunos pesquisados que responderam ao questionário composto de 20 questões nos proporcionou um rico material sobre a real situação dos alunos das escolas públicas brasileiras, onde foi verificado o sexo, a faixa etária, qunatitativo de pessoas que moram na mesma casa que o aluno, renda familiar, vida escolar, inflaestrutura do Colégio e utilização das TIC.

As questões de 03 a 06 abordam sobre a vida em família e a situação financeira dos entrevistados. Já sobre a vida escolar e os meios de comunicação que utilizam para se manterem informados estão presentes nas questões de 07 a 09. A questão 10 é sobre o lazer preferido. Questão o3 "Quantas pessoas moram na mesma casa que você?" e questão 04 "Quantas pessoas contribuem para a obtenção da renda de sua família?" Nove famílias têm de três a quatro pessoas trabalhando para obtenção da renda familiar, em 24 famílias somente uma pessoa trabalha para obtenção da renda familiar e em 56 famílias, duas pessoas trabalham para a obtenção da renda familiar. A Questão 05 "A renda mensal de sua família é:" 46,07\% recebem de dois a três salários mínimos. $33,71 \%$ recebem até um salário mínimo, $13,48 \%$ de 4 a 5 salários e somente 2,25\% das famílias recebem de seis a sete salários mínimos. Questão o6 "Qual a sua participação 
na vida econômica de sua família?” 96,63\% dependem financeiramente dos pais e/ou responsáveis. Questão 07 “Em sua vida escolar, você teve alguma reprovação?” 13 alunos já foram reprovados duas vezes, 13 alunos reprovados uma vez e aproximadamente $87 \%$ nunca foram reprovados. Questão o8 “Das disciplinas com maior afinidade?” Biologia (32 alunos), Matemática (23 alunos) e Língua Portuguesa (22 alunos). Questão o9 "Qual o meio de comunicação que você mais utiliza para se manter informado?" 82\% dos alunos utilizam a internet, 4\% rádio e 16\% a televisão. Questão 10 "Qual é o seu tipo de lazer predileto?” 37\% responderam que é se conectar à Internet, 33\% é encontrar os amigos e ir à festa com $24 \%$.

Sobre o contato com as TIC. “Utiliza computador?” 93,26\% utilizam computador, desses, 73\% utilizam o computador de suas residências. E “Navega na Internet?” Dos 89 alunos somente um respondeu não acessar a internet frequentemente, os demais navegam frequentemente. Sobre os "Aparatos tecnológicos utilizados para navegarem", 81\% dos alunos acessam a internet pelo seu próprio aparelho celular, computador e notebook. "Mudanças que ocorreram depois que passou a navegar na internet”. 66,29\% dos alunos responderam que a principal mudança foi conhecer pessoas e fazer amizades, $(24,72 \%)$ responderam para ficaram mais bem qualificados para o mercado de trabalho. "Navega a internet para:" acessar as redes sociais (71\%) dos alunos, seguido de $27 \%$ que acessam para ler as notícias e para pesquisas escolares no site da Google. A grande maioria dos alunos pesquisados possui uma renda familiar de até 3 salários mínimos, acessa a internet e têm facilidade com esse acesso.

Segundos dados do IBGE (2013) quando o critério é o uso da internet, a pirâmide social brasileira tem se tornado cada vez menos desigual. Em 2011, a população com renda per capita de até um salário mínimo passou a representar 38\% dos internautas do País, em 2005 esse grupo representava apenas $32 \%$ de internautas. O crescimento mais rápido ocorreu entre pessoas de 15 a 19 anos, cuja renda domiciliar per capita é inferior a um quarto do salário mínimo. Em 2005, apenas 3,8\% dessa população havia usado a internet nos três meses anteriores à pesquisa. Em 2011, esse índice saltou para 21,4\%, um número cinco vezes maior do que o da pesquisa anterior.

\section{Conclusões}

Os dados obtidos na pesquisa revelaram que os professores de Matemática do ensino médio possuem uma boa formação acadêmica e cursos de especialização, porém a maioria não possui formação específica para a inclusão das TIC nas atividades docentes. Verificou-se que os professores querem e sentem necessidade dessa formação continuada e que estão reivindicando políticas públicas, projetos e infraestrutura necessária como computadores e internet com qualidade.

Sobre as dificuldades na aprendizagem dos conteúdos de Matemática pelos alunos, os docentes apontam a falta de compromisso, interesse, foco dos alunos e a falta de conhecimento de conteúdos básicos de Matemática necessários para o entendimento dos conteúdos do ensino médio. Os professores afirmam ainda a importância de um bom relacionamento com os alunos, reconhecem a importância da inclusão de novas formas de ensinar, de conduzir o conhecimento, fazendo com que o aluno seja parte efetiva no mesmo.

Os dados analisados apontam a existência de outras TIC nos Colégios e a existência de laboratórios de informática que, no entanto, não funcionam. Os equipamentos são 
sucateados e não possuem assistência técnica. Além disso, não é possível contar mais com os dinamizadores, que eram parceiros dos professores na utilização dos laboratórios, do computador e na instalação de softwares. Enfim o professor se vê sem possibilidades de inserção dessas tecnologias em suas aulas. Vale ressaltar que apesar das dificuldades, há professores que ainda preparam um mínimo de aula com o uso das páginas da web para pesquisa na tentativa de que os alunos participem de alguma forma das atividades propostas pelos professores.

A análise dos dados aponta que a grande maioria dos alunos com idade entre de 16 a 18 anos de idade e com famílias (80\%) que recebem até três salários mínimos possuem um aparato tecnológico e vivem conectados com a internet, sendo as redes sociais os sites que mais acessam. Cabe ao sistema de ensino, a escola e ao professor buscar mecanismos para utilizar dessa facilidade e do interesse do aluno a favor da aprendizagem, já que a falta de interesse do aluno pelas aulas e pela escola está cada vez pior.

Sobre as TIC no processo de ensino e aprendizagem acredita-se que ela pode ser um dos caminhos que levam a construção do conhecimento na atualidade, uma vez que os jovens e as crianças estão cada vez mais inseridos nessa onda tecnológica. No entanto, a inserção das TIC nas ações pedagógicas não resolverá os problemas enfrentados pela educação.

\section{Referências}

Andrade, E. A.O, Silva, T. V. (2011). Os professores de Matemática e as TIC na educação tecnologia, mídias e educação. V Colóquio Internacional - Educação e Contemporaneidade.

Cachapuz, A. et al. A Necessária Renovação do Ensino das Ciências. São Paulo: Cortez, 2005. recebida por e-mail (iranete.lima@imag.fr) em 20 out. 2003.

Candau, V. M. F. (1997). Formação continuada de professores: tendências atuais. In: CANDAU, V. M. (Org.). Magistério: construção cotidiana. Petrópolis: Vozes, pp. 51-68.

Colette, M. M., \& Silva, M. H. C. D. (2014). Novos Cenários de Aprendizagem, Inovação e Sustentabilidade: Uma Pesquisa-Ação na Graduação em Ciências e Tecnologia. RISTI-Revista Ibérica de Sistemas e Tecnologias de Informação, (SPE2), pp. 55-69.

D’Ambrósio, U. (2002). Educação matemática: da teoria à prática. Livro da Série Perspectivas em Educação Matemática da SBEM.

Freire, P. (2003). Pedagogia do Oprimido. Rio de Janeiro: Paz e Terra.

Freire, P. (1999). Pedagogia da autonomia: saberes necessários à prática educativa. São Paulo: Paz e Terra.

Guajardo, H. (2001). La formación del profesor de matemática: um desafio complejo. VI reunion de didática de la matemática del cono sur. Argentina.

Gil, A. C. (2010). Métodos e Técnicas de Pesquisa Social. São Paulo: Atlas, 2010. 
Libâneo, J. C. (1991). Didática. São Paulo: Cortez.

Lüdke, M., \& André, M. E. (1986). Pesquisa em educação: abordagens qualitativas. Editora Pedagógica e Universitária.

Reis, L. R. (2014). Rejeição à matemática: causas e formas de intervenção. Disponível em: http://www.ucb.br/sites/100/103/tcc/12005/leonardorodriguesdosreis.pdf. Acesso em: 10 fev. 2015.

Reis, L. P., Barros, D., Vasconcelos, R., Costa, A. P., \& Faria, B. M. (2005). Perspetiva dos Diretores de Curso sobre a Escolha do Curso e Instituição dos Estudantes da Área de Engenharia em Portugal. RISTI-Revista Ibérica de Sistemas e Tecnologias de Informação, (SPE2), pp. 99-114.

Rodrigues, R. N. (2001). Relações com o saber: um estudo sobre o sentido da matemática em uma escola pública (Doctoral dissertation, Dissertação (Mestrado)-PUC, São Paulo).

Rudio, F. V. (1985). Introdução ao projeto de pesquisa científica. Vozes.

Santarosa, L. M. A., \& Gravina, M. (1998). aprendizagem da matemática em ambientes informatizados. In IV Congresso RIBIE. Brasília.

Tacca, M. C. V. R. (2006). Relações sociais na escola e desenvolvimento da subjetividade. MI Maluf et al., Aprendizagem: tramas do conhecimento, do saber e da subjetividade. Petrópolis, RJ: Vozes.

Valente, J. A. (2005). O salto para o futuro. Cadernos da TV-escola. Sede MEC, Brasília.

Vitti, C. M. (1999). Matemática com prazer, a partir da história e da geometria. $2^{\text {a }}$ Ed. Piracicaba - São Paulo. Editora UNIMEP, 103. 